\title{
Association of Functional Health Literacy with Glycemic Control: A Cross Sectional Study in Urban Population of Bangladesh
}

\author{
Refat Mehzabin, ${ }^{1}$ Kazi Jahangir Hossain, ${ }^{2}$ Md. Moniruzzaman, ${ }^{3}$ S K Jakaria Been Sayeed ${ }^{4}$
}

\begin{abstract}
Background: Diabetes mellitus is responsible for significant morbidity and mortality around the world though there is huge development regarding its treatment. Many studies showed that functional health literacy has a great impact on diabetes outcome. The study assessed the relationship between functional health literacy and glycemic control in a sample of urban diabetic patients.

Materials and methods: A cross-sectional study was conducted in Bangladesh University of Health and Science Hospital, Jurain, Dhaka from January to December 2014 that included adult diabetic patients on the basis of defined selection criteria following the purposive sampling method. Functional health literacy was assessed with the short form Test of the Functional Health Literacy in Adults (s-TOFLA). Recent $\mathrm{HbA} / \mathrm{c}$ was used as a measure of glycemic control and categorized into tight, fair and inadequate glycemic control. Regression models were controlled for demographic data, diabetes duration, treatment regimen, diabetes knowledge and assistance for taking medications.

Results: Following the s-TOFLA scale, $60.5 \%$ of the diabetic patients had inadequate functional health literacy of them, $89.3 \%$ had inadequate glycemic control (HbA/c>8\%). And those who had adequate functional health literacy (24\%) of them 68.8\% had tight glycemic control ( $\mathrm{HbAlc} \leq 7 \%$ ). Overall $63.0 \%$ of the respondents had inadequate glycemic control. In linear regression model low s-TOFLA scores, longer diabetes duration and lack of assistance for taking medications were associated with higher levels of $\mathrm{HbA}$ /c. In fully adjusted model s-TOFLA score was the variable which was more strongly associated with $\mathrm{HbAlc}(\beta=-0.60, P<0.00 \mathrm{I})$.
\end{abstract}

Conclusions: The study found that low health literacy is consistently associated with inadequate glycemic control.

Key words: Functional health literacy, Glycemic control, Diabetes mellitus, HbA/c.

DOI: http://dx.doi.org/l0.3329/jom.v20il.38816

Copyright: (C) 2019 Mehzabin $R$ et al. This is an open access article published under the Creative Commons Attribution-NonCommercial-NoDerivatives 4.0 International License, which permits use, distribution and reproduction in any medium, provided the original work is properly cited, is not changed in any way and it is not used for commercial purposes.

Received: 17 February, 2018;

Accepted: 23 May, 2018

1. Medical officer, Department of Labour, Ministry of Labour and Employment.

2. Assistant Professor, Department of Health Education, National Institute of Preventive and Social Medicine (NIPSOM), Mohakhali, Dhaka.

3. Medical Officer(OSD), Directorate General of Health Service (DGHS).

4. Medical Officer, Dept. of Medicine, Dhaka Medical College hospital, Dhaka.

Corresponding author: Dr. Refat Mehzabin, Medical officer, Department of Labour, Ministry of Labour and Employment, Bangladesh. Mobile:+8801716011432, Email: refatria@gmail.com.

\section{Introduction:}

The term 'functional health literacy' (FHL) has been used to imply one's ability to function adequately in healthcare settings, as determined by instruments which access basic skills needed to deal with health-related written materials. ${ }^{1,2}$ Low health literacy is recognized as a stronger predictor of a persons' health than age, income, employment status, education level, or race, and is associated with a wide range of adverse effects on care processes and health outcomes. ${ }^{3,4}$ Poor health literacy is more common among patients with chronic medical conditions, such as diabetes mellitus (DM), asthma, chronic obstructive pulmonary disease (COPD), 
acquired immunodeficiency syndrome (AIDS) and hypertension. ${ }^{5}$ Patients with poor health literacy have greater difficulties naming their medications and describing indications, more frequently hold health beliefs that interfere with adherence and are more likely to have poor understanding of their condition and its management. ${ }^{6}$ Inadequate FHL has been independently associated with poorer ability to take medications appropriately, lower utilization of preventive services, more hospitalizations, poorer overall health status and higher mortality rates. ${ }^{7,8}$

$\mathrm{DM}$ is a major disease that is becoming more prevalent, affecting more than 171 million people worldwide. According to the International Diabetes Federation (IDF) report (2011), Bangladesh now leads the world with 8.4 million diabetic patients, and this number is projected to increase to 16.8 million by the year $2030 .{ }^{9}$ In Bangladesh, a higher prevalence of diabetes was found in urban (8.1\%) compared with rural (2.3\%) populations. ${ }^{10}$ Poor FHL has been independently associated with worse glycemic control and good understanding of diabetes medications has been associated with better glycemic control. ${ }^{11}$ Several factors have been associated with poor glycemic control, including lower educational level, older age, lower income, longer diabetes duration, and lack of English language. Of these, lower education level and longer duration have consistently emerged as an independent risk factor for poor glycemic control. $^{12,13}$

The aim of the study was to assess the relationship between functional health literacy and glycemic control of diabetic patients among the urban population.

\section{Materials and methods:}

It was a cross-sectional study conducted among adult diabetic patients in Bangladesh University of Health and Science (BUHS) Hospital, Jurain, Dhaka from January 2014 to December 2014. Study participants were selected on the basis of defined selection criteria following the purposive sampling method where inclusion criteria were; age $\geq 18$ years, diabetes duration $>1$ year, had been taking anti-diabetic agents and had a recent Glycated haemoglobin (HbAlc) report. Patients were ineligible if they had visual, hearing, speech problem and cognitive impairment or had been suffering from myocardial infarction, stroke, end stage renal failure, thyroid dysfunction, and mental illness. Written informed consent was obtained before the interview. A semi structured questionnaire was developed to collect the data that was prepared by using the selected variables according to objectives including some scales related to study (sTOFLA, DKQ-10) and blood analysis report (HbA1c).

\section{Measures:}

FHL was assessed by the short form Test of the Functional Health Literacy in Adults (s-TOFLA), a validated instrument to evaluate the ability to read and understand health care information and medical advices given to the patients and categorize into inadequate (0-16), marginal (17-22) and adequate (23-36). ${ }^{14}$ Diabetic knowledge was assess by DKQ10 scale..$^{15}$ To measure glycemic control, HbAlc report was used. A rise of $1 \%$ in $\mathrm{HbA} 1 \mathrm{c}$ corresponds to an approximate average increase of $2 \mathrm{mmol} / \mathrm{L}(36 \mathrm{mg} / \mathrm{dL})$ in blood glucose. Normal range of $\mathrm{HbA} 1 \mathrm{c}$ is $4-6 \% .{ }^{16}$ According to $\mathrm{HbA} 1 \mathrm{c}$ the patients were categorize into tight control $(\leq 7 \%)$, fair control $(7.1-8 \%)$ and inadequate control $(>8 \%)$ of diabetes. ${ }^{17}$

Statistical analysis:

Data were analyzed by using SPSS (statistical package for social science) statistical software version 21.0 for windows. The findings of the study were presented by frequency, percentage in tables. Mean and standard deviation (SD) for continuous variables and frequency distribution for categorical variable were used to describe the characteristics of the total sample. Relationships of the categorical data were assessed using ANOVA, Fisher exact and Chi-square test. Regression analyses were used to explore the association between functional health literacy and glycemic control while controlling for other potentially confounding variables. In primary analyses, functional health literacy and glycemic control were used as continuous variables in multiple linear regressions. In these models, $\mathrm{HbA} 1 \mathrm{c}$ was the dependent variable and FHL was the primary independent variable.

\section{Results:}

Study sample consisted of 200 adult diabetic patients with a mean age of 48.86 years $(\mathrm{SD} \pm 10.4)$ where 137 patients were female and 63 were male. Among them $58.5 \%$ had been suffering from DM more than 5 years and receiving oral antidiabetic agents (OADs) (58.5\%), combination of OADs and insulin $(29.5 \%)$ or insulin alone (12\%). The mean HbAlc of the study population was $8.97 \%(\mathrm{SD} \pm 1.9)$ and $63 \%$ patients had inadequate glycemic control (HbA1c $>8 \%$ ), 17\% fair control (HbA1c 7.1-8\%) and tight glycemic control (HbA1c $\leq 7 \%$ ) in $20 \%$. Inadequate health literacy (s-TOFLA, $0-16$ ) was found in $60.5 \%$ respondents, marginal (s-TOFLA, 17 22) $15.5 \%$ and $24.0 \%$ had adequate (s-TOFLA, 23-36) health literacy. Inadequate health literacy was more likely in patients with age $>40$ years, female, undergraduates, home makers, those with diabetes duration more than 5 years and patients receiving OADs $(\mathrm{p}<0.05)$ (Table I). The participants who had inadequate FHL, most of them ( $89.3 \%$ ) had poor glycemic 
control and those who had adequate FHL, of them $68.8 \%$ had tight glycemic control (Table II). In linear regression model low s-TOFLA scores, longer diabetes duration and lack of assistance for taking medications were associated with higher levels of HbA1c. After adjustment for age, sex, education, occupation, treatment regimen, assistance, duration of disease and diabetes knowledge; only the sTOFLA score, diabetes duration and lack of assistance were independently very strongly associated with $\mathrm{HbAlc}(\mathrm{P}<0.001)$ (Table III). For each 1 SD increase in s-TOFLA score, the $\mathrm{HbA1c}$ value would be decreased by 0.60 and thus improve glycemic control. In fully adjusted model s-TOFLA score was the variable more strongly associated with $\mathrm{HbAlc}(\beta=-0.60$, $\mathrm{P}<0.001)$. It means that if all other variables remained constant, a 1 SD increase on s-TOFLA score would be associated with an improvement of $0.60 \mathrm{SD}$ on predicted $\mathrm{HbA} 1 \mathrm{c}$.

\section{Table I}

Characteristics of the patient stratified by functional health literacy level.

\begin{tabular}{|c|c|c|c|c|c|c|}
\hline \multirow[t]{2}{*}{ Characteristics } & & \multicolumn{3}{|c|}{ Functional health Literacy Level } & \multirow{2}{*}{$\begin{array}{c}\text { Total } \\
(\mathrm{n}=200)\end{array}$} & \multirow{2}{*}{$\begin{array}{c}\mathrm{P} \\
\text { value }\end{array}$} \\
\hline & & $\begin{array}{c}\text { Inadequate } \\
(0-16) \\
(\mathrm{n}=121)\end{array}$ & $\begin{array}{c}\text { Marginal } \\
(17-22) \\
(\mathrm{n}=31) \\
\end{array}$ & $\begin{array}{c}\text { Adequate } \\
(23-36) \\
(n=48)\end{array}$ & & \\
\hline \multirow[t]{4}{*}{ Education } & Illiterate & $20(16.5 \%)$ & $2(6.5 \%)$ & $1(2.1 \%)$ & $23(11.5 \%)$ & $\mathrm{P}<0.001$ \\
\hline & Primary completed & $8(6.6 \%)$ & $2(6.5 \%)$ & $0(0 \%)$ & $10(5.0 \%)$ & \\
\hline & Under graduate & $50(41.4 \%)$ & $6(17.0 \%)$ & $5(10.9 \%)$ & $61(30.5 \%)$ & \\
\hline & Graduate & $43(35.5 \%)$ & $28(67.8 \%)$ & $42(87.6 \%)$ & $106(53.0 \%)$ & \\
\hline \multirow[t]{6}{*}{ Occupation } & Service & $10(8.3 \%)$ & $10(32.3 \%)$ & $35(72.9 \%)$ & $55(27.5 \%)$ & $\mathrm{P}<0.001$ \\
\hline & Business & $17(14.0 \%)$ & $5(16.1 \%)$ & $3(6.2 \%)$ & $25(12.5 \%)$ & \\
\hline & Home maker & $89(73.6 \%)$ & $15(48.4 \%)$ & $8(16.7 \%)$ & $112(56.0 \%)$ & \\
\hline & Retired & $1(0.8 \%)$ & $0(0 \%)$ & $1(2.1 \%)$ & $2(1.0 \%)$ & \\
\hline & Student & $2(1.7 \%)$ & $1(3.2 \%)$ & $1(2.1 \%)$ & $4(2.0 \%)$ & \\
\hline & Others & $2(1.7 \%)$ & $0(0 \%)$ & $0(0 \%)$ & $2(1.0 \%)$ & \\
\hline \multirow[t]{5}{*}{ Diabetes duration (Year) } & $\leq 5$ & $24(19.9 \%)$ & $15(48.4 \%)$ & $44(97.7 \%)$ & $83(41.5 \%)$ & $\mathrm{P}<0.001$ \\
\hline & $6-10$ & $72(59.5 \%)$ & $13(41.9 \%)$ & $3(6.2 \%)$ & $88(44.0 \%)$ & \\
\hline & $11-15$ & $17(14.0 \%)$ & $0(0 \%)$ & $1(2.1 \%)$ & $18(9.0 \%)$ & \\
\hline & $16-20$ & $7(5.8 \%)$ & $3(9.7 \%)$ & $0(0 \% 0$ & $10(5.0 \%)$ & \\
\hline & $>20$ & $1(0.8 \%)$ & $0(0 \%)$ & $0(0 \%)$ & $1(0.5 \%)$ & \\
\hline \multirow[t]{3}{*}{ Treatment regimen } & Insulin & $16(13.2 \%)$ & $4(12.9 \%)$ & $4(8.3 \%)$ & $24(12.0 \%)$ & $\mathrm{P}<0.001$ \\
\hline & OADs & $57(47.1 \%)$ & $20(64.5 \%)$ & $40(83.3 \%)$ & $117(58.5 \%)$ & \\
\hline & Insulin + OADs & $48(39.7 \%)$ & $7(22.6 \%)$ & $4(8.3 \%)$ & $59(29.5 \%)$ & \\
\hline \multirow[t]{2}{*}{ Other's assistance } & Yes & $9(7.4 \%)$ & $3(9.7 \%)$ & $2(4.2 \%)$ & $14(7.0 \%)$ & $\mathrm{P}=0.616$ \\
\hline & No & $112(92.6 \%)$ & $28(90.3 \%)$ & $46(95.8 \%)$ & $186(93.0 \%)$ & \\
\hline \multirow[t]{2}{*}{ Diabetes knowledge } & $\operatorname{Good}(>7)$ & $102(84.3 \%)$ & $28(90.3 \%)$ & $44(91.7 \%)$ & $174(87.0 \%)$ & $\mathrm{P}=0.366$ \\
\hline & Average (5-7) & $19(15.7 \%)$ & $3(9.7 \%)$ & $4(8.3 \%)$ & $26(13.0 \%)$ & \\
\hline
\end{tabular}

Table-II

Functional health literacy and HbAlc of the patients $(n=200)$

\begin{tabular}{|c|c|c|c|c|}
\hline \multirow[t]{2}{*}{ Glycemic control } & \multicolumn{3}{|c|}{ Functional health literacy } & \multirow{2}{*}{$\begin{array}{c}\text { Total } \\
(n=200)\end{array}$} \\
\hline & $\begin{array}{l}\text { Inadequate }(0-16) \\
(\mathrm{n}=121)\end{array}$ & $\begin{array}{c}\text { Marginal }(17-22) \\
(\mathrm{n}=31)\end{array}$ & $\begin{array}{c}\text { Adequate }(23-36) \\
(n=48)\end{array}$ & \\
\hline Tight $(\leq 7 \%)$ & $5(4.1 \%)$ & $2(6.5 \%)$ & $33(68.8 \%)$ & $40(20.0 \%)$ \\
\hline Fair $(7.1-8 \%)$ & $8(6.6 \%)$ & $13(41.9 \%)$ & $13(27.1 \%)$ & $34(17.0 \%)$ \\
\hline Inadequate $(>8 \%)$ & $108(89.3 \%)$ & $16(51.6 \%)$ & $2(4.2 \%)$ & $126(63.0 \%)$ \\
\hline
\end{tabular}


Table 3: Association between patients characteristics and HbAlc $(n=200)$

\begin{tabular}{lcccccc}
\hline Model & $\mathrm{R}$ & $\mathrm{R}^{2}$ & Adjusted $\mathrm{R}^{2}$ & $\mathrm{Df}$ & $\mathrm{F}$ & $\mathrm{Sig}$ \\
\hline Regression & 0.79 & 0.63 & 0.60 & 14 & 22.4 & 0.000 \\
Residual & & & & 185 & & \\
\hline Characteristics & Unstandardized & Coefficients & Standardized & $\mathrm{t}$ & P value \\
& & & Coefficients & & \\
& $\mathrm{B}$ & $\mathrm{SE}$ & Beta & & \\
\hline Constant & 7.00 & 1.82 & & 3.85 & 0.000 \\
Age & -0.02 & 0.01 & -0.08 & -1.06 & 0.289 \\
Sex & -0.06 & 0.25 & -0.01 & -0.24 & 0.810 \\
Education & -0.07 & 0.11 & -0.06 & -0.62 & 0.537 \\
Occupation & 0.06 & 0.12 & 0.03 & 0.48 & 0.633 \\
Diabetes duration & 0.12 & 0.03 & 0.26 & 3.48 & 0.001 \\
Treatment regimen & -0.006 & 0.15 & -0.002 & -0.04 & 0.970 \\
Other's assistancy & 2.62 & 0.41 & 0.35 & 6.44 & 0.000 \\
Diabetes knowledge & 0.05 & 0.11 & 0.03 & 0.50 & 0.616 \\
S-TOFLA score(0-36) & -0.16 & 0.02 & -0.60 & -8.73 & 0.000 \\
\hline
\end{tabular}

\section{Discussion:}

Health literacy is an important issue because limited health literacy is linked to several adverse health related variables including more hospitalization, poorer ability to take medications appropriately. Inadequate health literacy is a stronger indicator of uncontrolled diabetes and its complications. The study demonstrated that age, sex, education, occupation, diabetes duration, treatment regimen, lack of assistance for taking medications and inadequate FHL were associated with inadequate glycemic control. This study also revealed patients receiving OADs have inadequate FHL and inadequate glycemic control which corresponds with the results of Schillinger et $\mathrm{al}^{18}$ and female home maker had both inadequate FHL and inadequate glycemic control which corresponds with kim et al. ${ }^{19}$ These results corresponds with our cultural aspect as home makers have lack of information and most of the patients in our country have a fear of insulin therapy, thus they prefer OADs. Hoque et $\mathrm{al}^{20}$ showed that in Bangladesh, nearly $86 \%$ of patients with diabetes have completed only high school or less as well as $62 \%$ were housewife, which corresponds with our result. Sayah et $\mathrm{al}^{21}$ disclosed that in a systemic review of health literacy and health outcomes in diabetes, 8 studies showed consistent and sufficient evidence of a positive association between health literacy and diabetes knowledge which did not corresponds with present study.
This study demonstrated that inadequate FHL was associated with a higher rate of inadequate glycemic control that was consistent with the study reported by Souza et al ${ }^{17}$ who studied a sample of low educated Brazilian patients in Sao Paulo using SAHLPA-18 score for measurement of FHL. Schillinger et $\mathrm{al}^{6}$ conducted a study with a sample of patients in San Francisco where FHL were measured by s-TOFLA and found strong association between inadequate FHL and poorer glycemic control. The proportion of patients with tight glycemic control vs inadequate control is routinely used as a quality of care indicator for diabetes. HbAlc is an objective of clinical end point that has been linked to health care use and costs and disabling and life threatening condition (Devidson, 22nd). ${ }^{22}$ After conducting a systemic review, Boren ${ }^{23}$ suggested that a confounder could explain the inconsistency in results across studies designed to investigate the effects of health literacy on glycemic control. Significant association between FHL and glycemic control were found most of the studies that did not adjust for diabetes knowledge. Our study brought a new piece of evidence which is contrary to that hypothesis. The study was controlled for diabetes knowledge and had still found a significant association between FHL and glycemic control. In this study diabetes knowledge had no significant association with FHL $(\mathrm{P}=0.366)$ as well as glycemic control $(\mathrm{P}=0.699)$.

Contrary to expectations, some illiterate patients did not have inadequate glycemic control though they had inadequate 
FHL. The reason might be illiterate patients were aged, thus had assistance for taking medications. In an Iranian diabetes clinic, Jahanlou and Karami ${ }^{24}$ did not find a significant difference in HbA1c levels between illiterate and literate patients. Similarly, Hawthorne and Tomlinson ${ }^{25}$ reported comparable levels of $\mathrm{HbA} 1 \mathrm{c}$ between illiterate and literate Pakistani patients with type 2 diabetes. Bennett et $\mathrm{al}^{26}$ demonstrated that slum and under privileged people had low level of literacy which we could not assessed because none of our patients were from that socio economic status. Jeppensen et $\mathrm{al}^{27}$ found illiterate people had inadequate glycemic control which did not corresponds with our study as though a little of the participants were illiterate, they had assistance for taking medication. This study did not include a specific instrument to assess social support, which would have allowed to explore a possible interaction of this factor with FHL in determining glycemic control which different studies done.

\section{Conclusions:}

Our study indicates that the current understanding of the effect of low health literacy on health of the people with diabetes is limited. Knowledge regarding diabetes alone, however, is not associated with better glycemic control. Though, this study had a number of important implications, from the public health standpoint, these findings can inform strategic plans to address the growing diabetes epidemic.

\section{Limitations:}

It was a cross-sectional study and did not allow to ascertain whether inadequate health literacy was causally associated with poor glycemic control. The study was done among urban population where health care facilities were available and accessible but will differ in rural areas. Large scale comparative study should be carried out to see the exact situation of Bangladesh.

\section{Conflict of interest: None.}

\section{References:}

1. Baker DW, Parker RM, Williams MV et al. The health care experience of patients with low literacy. Arch Fam Med 1996;5:329-34. https://doi.org/10.1001/archfami.5.6.329

2. Speros CI, Health Literacy: concept analysis. Journal of Advanced Nursing 2005;50(6):633-40. https://doi.org/ 10.1111/j.1365-2648.2005.03448.x

3. Speros CI, Promoting Health Literacy: A Nursing Imperative. Nurs Clin N Am 2011; 46: 321-33. https://doi.org/10.1016/ j.cnur.2011.05.007

4. Baker Dw, Gazmararian JA, Sudano J et al. The Association Between Age and Health Literacy Among Elderly Persons.
Journal of Gerontology: Social Sciences 2000;55(B-6):S36874. https://doi.org/10.1093/geronb/55.6.S368

5. Carol AM and Melina R. Impact of Health Literacy on Longitudinal Asthma Outcomes. CJ Gen Intern Med. 2006;21(8):813-817. https://doi.org/10.1111/j.15251497.2006.00528.x

6. Schillinger D, Bindman A, Frances W et al. Functional health literacy and the quality of physician-patient communication among diabetes patients. Patient Education and Counseling, 2003;288(03):107-17.

7. Gazmararian JA, Williams MV, Peel J, Baker DW. Health literacy and knowledge of chronic disease. Patient Educ Coun, 2003;51(3):267-75. https://doi.org/10.1016/S07383991(02)00239-2

8. Gazmararian JA, Baker DW, Williams MV et al. Health literacy among Medicare enrollees in a managed care organization. JAMA 1999;281:545-51. https://doi.org/ 10.1001/jama.281.6.545

9. Saleh F, Mumu SJ, Ara F et al. Knowledge and self-care practices regarding diabetes among newly diagnosed type 2 diabetics in Bangladesh: a cross-sectional study. BMC Public Health, 2012;12:111-15. https://doi.org/10.1186/14712458-12-1112

10. Bhowmik B, Afsana F, Lien MD et al. Increasing Prevalence of Type 2 Diabetes in a Rural Bangladeshi Population: A Population Based Study for 10 Years. Diabetes Metab J. 2013;37:46-53. https://doi.org/10.4093/dmj.2013.37.1.46

11. Hussain A, Rahim MA, Khan AKA et al. Type 2 diabetes in rural and urban population: diverse prevalence and associated risk factors in Bangladesh. UK Diabetic Medicine, 2005;22:931-36. https://doi.org/10.1111/j.14645491.2005.01558.x

12. Mahtab H, Khan AR, Latif ZA et al. Guidelines for care of type 2 diabetes mellitus in Bangladesh. Dhaka: BIRDEM Clinical Research Group, 2003; 10: 40-43.

13. Woodard LD, Landrum CR, Amspoker AB et al. Interaction between functional health literacy, patient activation, and glycemic control. Patient Prefer Adherence, 2014; 8: 101924. https://doi.org/10.2147/PPA.S63954

14. Baker DW, Williams MV, Parker RM et al. Development of a brief test to measure functional health literacy. Patient Education and Counseling. 1999; 38: 33-42. https://doi.org/ 10.1016/S0738-3991(98)00116-5

15. Al-Adsani AMS, Moussa MAA, Al-Jasem LI, et al. The level and determinants of diabetes knowledge in Kuwaiti adults with type 2 diabetes. Diabetes \& Metabolism 2009;35:121-128. https://doi.org/10.1016/j.diabet.2008.09 .005

16. Department of Medicine, Medical University of South Carolina, Charleston, South Carolina, USA. Associations 
between health literacy, diabetes knowledge, self-care behaviors, and glycemic control in a low income population with type 2 diabetes. Diabetes Technology \& amp Therapeutics. 2011;13(3):335-41. https://doi.org/10.1089/ dia. 2010.0160

17. Souza JG, Apolinario D, Magaldi RM et al. Functional health literacy and glycaemic controlin older adults with type 2 diabetes: a cross-sectional study. BMJ Open 2014; 4:e004180. doi:10.1136/bmjopen-2013-004180. https:// doi.org/10.1136/bmjopen-2013-004180

18. Schillinger D, Grumbach K, Piette J et al. Association of Health literacy with Diabetes Outcomes, JAMA 2002;288:475-82. https://doi.org/10.1001/jama.288.4.475

19. Kim S, Frances L, Alex Q, Bajudy AS. Association of Health Literacy with Self- Management Behavior in Patients with Diabetes. Diabetes Care, 2004;27(12):1047-1053. https:// doi.org/10.2337/diacare.27.12.2980

20. Hoque MA, Islam A, Khan AM, Ahasan N. Knowledge of diabetic Complications in a diabetic population, J Medicine 2009;10:90-93. https://doi.org/10.3329/jom.v10i2.2821

21. Sayah FA, Majumdar SR, Williams B et al. Health Literacy and Health Outcomes in Diabetes: A Systematic Revie. J Gen Intern Med, 2012;28(3):444-52. https://doi.org/10.1007/ s11606-012-2241-z
22. College NR, Walker BR and Ralston SH. Davidson's Principles and Practice of Medicine 22nd edition, Churchill, Livingstone; 2014:797-36.

23. Boren SA. A Review of Health Literacy and Diabetes: Opportunities for Technology, J Diabetes Sci Technol 2009;3(1):202-209. https://doi.org/10.1177/193229680900300124

24. Jahanlou AS and Karami NA, The effect of literacy level on health related-quality of life, self-efficacy and selfmanagement behaviors in diabetic patients. Acta Med Iran, 2011;49:153-58.

25. Hawthorne K and Tomlinson S. Pakistani Muslims with type 2 diabetes mellitus: effect of sex, literacy skills, known diabetic complications and place of care on diabetes knowledge, reported self-monitoring management and glycaemic control. Diabet Med 1999;16:591-97. https:// doi.org/10.1046/j.1464-5491.1999.00102.x

26. Bennett IM, Chen J, Soroui JS et al. The contribution of health literacy to disparities in self-rated health status and preventive health behaviors in older adults. Ann Fam Med. 2009;7(3):204-11. https://doi.org/10.1370/afm.940

27. Jeppesen KM, Coyle JD, and Miser WF. Screening Questions to Predict Limited Health Literacy: A CrossSectional Study of Patients with Diabetes Mellitus. Annals of Family Medicine, 2009,7(1):2-6. https://doi.org/10.1370/ afm.919 